\title{
Meningitis and pneumonia in Guatemalan children: the importance of Haemophilus influenzae type b and Streptococcus pneumoniae
}

\author{
Edwin J. Asturias,,$^{1,2}$ Monica Soto, ${ }^{3}$ Ricardo Menendez, ${ }^{4}$ \\ Patricia L. Ramirez, ${ }^{3}$ Fabio Recinos, ${ }^{5}$ Remei Gordillo, ${ }^{4}$ \\ Elizabeth Holt, ${ }^{1}$ and Neal A. Halsey ${ }^{1}$
}

ABSTRACT Objective. To determine the epidemiology of Haemophilus influenzae type $b$ (Hib) and Streptococcus pneumoniae invasive infections in hospitalized Guatemalan children. This is an important issue since Hib vaccine has not been incorporated into the routine immunization program in Guatemala and information from hospital records in 1995 indicated a low incidence of Hib and S. pneumoniae as causes of meningitis and invasive infections.

Methods. Children who were hospitalized in Guatemala City with clinical signs compatible with bacterial infections were evaluated for evidence of Hib or S. pneumoniae infection. Normally sterile body fluids were cultured, and antigen detection was performed on cerebrospinal fluid (CSF) and pleural fluid.

Results. Of 1203 children 1-59 months of age hospitalized over a 28-month period, 725 of them $(60.3 \%)$ had a primary diagnosis of pneumonia, $357(29.7 \%)$ of meningitis, $60(5.0 \%)$ of cellulitis, and 61 (5.1\%) of sepsis and other conditions. Hib was identified in $20.0 \%$ of children with meningitis and S. pneumoniae in $12.9 \%$. The average annual incidence of Hib meningitis was 13.8 cases per 100000 children under 5 years of age, and 32.4\% of meningitides caused by Hib and 58.7\% of S. pneumoniae meningitides occurred prior to 6 months of age. Case fatality rates were $14.1 \%, 37.0 \%$, and $18.0 \%$, respectively, for children with Hib, S. pneumoniae, and culture-negative and antigen-negative meningitis. Prior antibiotic therapy was common and was associated with significant reductions in CSF-culture-positive results for children with other evidence of Hib or S. pneumoniae meningitis.

Conclusions. Improvements in case detection, culture methods, and latex agglutination for antigen detection in CSF resulted in identification of Hib and S. pneumoniae as important causes of severe disease in Guatemalan children. Using a cutoff of $>10$ white blood cells per cubic millimeter in CSF would improve the sensitivity for detection of bacterial meningitis and help estimate the burden of bacterial meningitis in Guatemala and other developing countries.

Key words Haemophilus influenzae type b; meningitis, Haemophilus; Streptococcus pneumoniae; vaccination; Guatemala.

\footnotetext{
Johns Hopkins Bloomberg School of Public Health, Department of International Health, Baltimore, Maryland, United States of America. Send correspondence to: Neal A. Halsey, Johns Hopkins Bloomberg School of Public Health, 615 N. Wolfe St., W5401, Baltimore, Maryland 21205, United States of America; telephone: 410-955-6964; fax:
}

410-502-6733; e-mail: nhalsey@jhsph.edu (no reprints available).

2 The Center for Disease Studies and Control, Guatemala City, Guatemala.

3 Hospital General San Juan de Dios, Department of Pathology, Guatemala City, Guatemala.
Hospital Roosevelt, Department of Pathology, Guatemala City, Guatemala.

5 Hospital General del Instituto Guatemalteco de Seguridad Social, Department of Pediatrics, Guatemala City, Guatemala. 
In many industrialized countries the incidence of invasive disease caused by Haemophilus influenzae type b (Hib) decreased dramatically following widespread use of Hib conjugate vaccines (1-5). Before these vaccines were available, an estimated one in 200 children in the United States of America developed invasive Hib disease before 5 years of age (1). Information from a limited number of developing countries in Africa, Asia, and Latin America indicates that $\mathrm{Hib}$ is an important cause of childhood morbidity and mortality, responsible for $25 \%-65 \%$ of bacterial meningitis as well as $15 \%$ $25 \%$ of severe pneumonia in some areas (4-9). Case fatality rates for meningitis in developing countries are often higher than reported in developed countries because of delays in diagnosis and suboptimal antimicrobial therapy (4,10-13). Conjugate vaccines offer the potential for preventing these important causes of morbidity and mortality, but the importance of Hib and Streptococcus pneumoniae is often underappreciated due to failure to obtain cultures from sick children and suboptimal microbiologic methods. Introduction of Hib vaccines in developing countries like Guatemala has progressed slowly, despite evidence of its effectiveness. Decision makers in developing countries need data before committing limited resources for the purchase of relatively expensive vaccines. Since Hib vaccine had not been incorporated into the public routine immunization program in Guatemala, we initiated a surveillance program to detect invasive diseases caused by $\mathrm{Hib}$ and S. pneumoniae in order to estimate the burden of severe disease in children in Guatemala City.

\section{METHODS}

\section{Study population}

Between 1 October 1996 and 31 January 1999 we evaluated children 1 to 59 months of age admitted with clinical signs compatible with bacterial infections to the three major referral hospitals in Guatemala City. We prospectively determined the proportion of infections caused by $\mathrm{Hib}$ and $S$. pneumoniae. The three hospitals-Hospital General San Juan de Dios, Hospital Roosevelt, and Hospital General del Instituto Guatemalteco de Seguridad Social (IGSS) (Spanish name) - capture approximately $85 \%$ of Guatemala City children hospitalized with meningitis. Private hospitals and sanatoriums serve the remaining $15 \%$ of children presenting with these illnesses. These major referral hospitals also serve adjacent municipalities surrounding Guatemala City, which together constitute the Guatemalan metropolitan area. The proportion of children who reside in the surrounding metropolitan area and who develop serious infections resulting in referral to these hospitals is unknown. For this reason we calculated incidence rates only for children who lived in Guatemala City; the remaining analyses include all eligible children, regardless of residence. Based on projections from the 1994 census, the National Statistics Institute estimates that 326779 children less than 5 years of age were living in the Guatemalan metropolitan area in 1997; of these, 121003 were living in Guatemala City.

\section{Case definitions}

Children with possible invasive bacterial disease were identified by daily reviews of admission logbooks and laboratory results at each institution. Meningitis was defined as either a cerebrospinal fluid (CSF) white blood cell count $(\mathrm{WBC}) \geq 10$ cells $/ \mathrm{mm}^{3}$ or a positive bacterial culture or latex agglutination antigen test for Hib or $S$. pneumoniae in the CSF. Data were also analyzed using the World Health Organization (WHO) definition of probable meningitis: CSF protein $>100$ $\mathrm{mg} / \mathrm{dL}$ or glucose $<40 \mathrm{mg} / \mathrm{dL}$ or $\mathrm{WBC}>100 / \mathrm{mm}^{3}$ with $>80 \%$ neutrophils. Bacterial meningitis was confirmed by a positive bacterial CSF culture or latex agglutination antigen test for Hib or S. pneumoniae (14). A child was diagnosed as having pneumonia if he or she had fever, cough, tachypnea, and/or a chest radiograph showing infiltrates. Children with wheezing were excluded unless the chest radiograph revealed lobar consolidation; we did that because the primary purpose of this study was to identify children with bacterial disease. Confirmed bacterial pneumonia was defined as detection of any bacteria by blood or pleural fluid culture or a positive pleural fluid latex agglutination test for Hib or S. pneumoniae. The admitting physician diagnosed sepsis based on fever and signs of severe illness (e.g., toxic appearance and hypotension). A child with meningitis, pneumonia, and/or sepsis was classified as having a primary diagnosis of meningitis. A child with sepsis and pneumonia was classified as having pneumonia. Clinical signs of septic arthritis, epiglottitis, pericarditis, abscess, or cellulitis were used to define these other invasive bacterial diseases. For these illnesses, Hib or S. pneumoniae disease was diagnosed by culture from blood or other normally sterile fluid.

\section{Laboratory procedures}

A preliminary review of 365 CSF samples obtained in one of the hospitals in 1995 from children suspected of having meningitis revealed only one Hib isolate and one S. pneumoniae isolate. The chocolate agar used in the hospitals at that time was made from discarded human blood. This agar was demonstrated to be less sensitive than commercial chocolate agar supplemented with IsoVitaleX ${ }^{\mathrm{TM}}$ (Becton Dickinson Microbiology Systems, Cockeysville, Maryland, United States), based on serial dilution of a log phase growth of Hib. Prior to initiating surveillance, the laboratories began using supplemented commercial chocolate agar.

Blood cultures were obtained at the discretion of the admitting physicians. Blood was cultured in brain-heart infusion broth supplemented with sodium polyanethol sulfonate (SPS). 
Subcultures on IsoVitale $\mathrm{X}^{\mathrm{TM}}$-enriched chocolate agar and MacConkey agar were performed at 24 hours and, if turbidity developed, in the next 7 days. In May 1997, automated blood cultures for detection of bacterial growth (BACTEC, Becton Dickinson Microbiology Systems, Lutherville, Maryland, United States) were introduced at two of the hospitals; that was done at the third hospital in January 1998. Cerebrospinal fluid, pleural fluid, and fluid from other normally sterile sites were also cultured in broth and on IsoVitale $\mathrm{X}^{\mathrm{TM}}$-enriched chocolate agar and MacConkey agar following standard procedures. H. influenzae isolates were confirmed as serotype $b$ by detection of Hib antigen by latex agglutination (Directigen, Becton Dickinson Microbiology Systems, Lutherville, Maryland, United States) in the same body fluid or supernatant of broth cultures. Isolates with colony morphology consistent with S. pneumoniae were confirmed by optochin disk sensitivity. Aliquots of CSF, serum, pleural fluid, and other usually sterile fluids were stored at $2{ }^{\circ} \mathrm{C}$ to $8{ }^{\circ} \mathrm{C}$ and tested within 24 hours for Hib and $S$. pneumoniae antigens by latex agglutination. Prior to being tested, sera, pleural fluid, and joint fluid were heattreated in accordance with the manufacturer's recommendations. Testing of sera was discontinued after the first year because of the limited added value and the high cost of the tests. Antigen testing for all other fluids was conducted throughout the surveillance period.

\section{Statistical methods}

Data were collected on standard forms, entered into a database using Epi Info version 6.0 software (Centers for Disease Control and Prevention, Atlanta, Georgia, United States), and analyzed using SPSS-PC version 10 software (SPSS, Inc., Chicago, Illinois, United States). Proportions were compared using two-tailed chi-square or Fisher's exact tests. Meningitis incidence rates for Guatemala City resi- dents were estimated based on the city's projected population of children less than 5 years of age in 1997 and the assumption that $85 \%$ of Guatemala City children with meningitis were cared for at the three study hospitals.

\section{Ethical reviews}

The Committee on Human Research of the Bloomberg School of Public Health of Johns Hopkins University and the board for research and education at each hospital approved the study.

\section{RESULTS}

Of the 1203 children studied, 1080 $(89.8 \%)$ had cultures of blood or usually sterile body fluids. Blood culture isolation rates were significantly improved $(P<0.001)$ following the introduction of the automated blood culture systems, from $6.3 \%(24 / 384)$ to $14.4 \%$ (72/501). Receipt of antibiotics prior to admission was reported for $563(46.8 \%)$ of the children. Meningitis and pneumonia were the diseases most commonly associated with Hib and S. pneumoniae infections (Table 1). The highest incidence of $\mathrm{Hib}$ and $S$. pneumoniae was in the first 12 months of age, and $33.3 \%$ of $\mathrm{Hib}$ and $37.7 \%$ of S. pneumoniae occurred before 6 months of age (Figure 1).

\section{Meningitis}

Of the 357 children with meningitis, 87 of them $(24.4 \%)$ also had pneumonia, $7(2 \%)$ had sepsis, and $4(1.1 \%)$ had both pneumonia and sepsis. Of the 357, 204 of them $(57.1 \%)$ were male. Bacterial etiology was confirmed in 157 of the 357 children (44.0\%), 146 by positive CSF culture or antigen test and 11 by a positive blood culture and inflammatory changes in the CSF. Of the 157 bacteriologically confirmed cases of meningitis, Hib was identified in $71(45.2 \%)$ and S. pneumoniae in 46 (29.3\%) (Table 1). Among these cases of bacterial meningitis, Directigen antigen detection identified 26 of the 71 cases of meningitis due to Hib $(36.6 \%)$ and 10 of the 46 cases of $S$. pneumoniae meningitis $(21.7 \%)$ not detected by CSF or blood cultures. Two false-positive CSF Hib latex agglutination tests were observed. In one of those tests a child had S. aureus isolated from CSF. In the other falsepositive test a child had S. aureus bacteremia associated with a peripheral white blood cell count of 51810 and the CSF culture had no growth; the

TABLE 1. Distribution of invasive diseases by etiology and diagnosis for children 1-59 months of age, Guatemala City, Guatemala, 1 October 1996-31 January 1999

\begin{tabular}{|c|c|c|c|c|c|c|}
\hline Diagnosis & $\begin{array}{l}\text { Haemophilus } \\
\text { influenzae }\end{array}$ & $\begin{array}{l}\text { Streptococcus } \\
\text { pneumoniae }\end{array}$ & $\begin{array}{c}\text { Other } \\
\text { bacteria }\end{array}$ & $\begin{array}{l}\text { No } \\
\text { organisms } \\
\text { found }\end{array}$ & $\begin{array}{l}\text { Total cases } \\
\text { with culture } \\
\text { or latex } \\
\text { agglutination }\end{array}$ & Total \\
\hline Meningitis & 71 & 46 & $40^{a}$ & 200 & 357 & 357 \\
\hline Pneumonia & 24 & 30 & $34^{b}$ & 612 & 700 & 725 \\
\hline Sepsis & 3 & 1 & 0 & 29 & 33 & 34 \\
\hline Cellulitis & 6 & 0 & 1 & 49 & 56 & 60 \\
\hline Septic arthritis & 1 & 0 & 2 & 6 & 9 & 9 \\
\hline Epiglottitis & 2 & 0 & 0 & 1 & 3 & 3 \\
\hline Other & 0 & 0 & 0 & 4 & 4 & 15 \\
\hline Total & 107 & 77 & 77 & 901 & 1162 & 1203 \\
\hline
\end{tabular}

a These 40 "other bacteria" were: Neisseria meningitis (7), Salmonella spp. (8), Staphylococcus aureus (8), Escherichia coli (4), Pseudomonas aeruginosa (5), and other organisms, including Streptococcus spp. and other enteric gram-negative bacteria (8).

b These 34 "other bacteria" were: S. aureus (21), Streptococcus spp. (6), Salmonella spp.(1), E. coli (1), P. aeruginosa (3), and other gram-negative bacteria (2). 
FIGURE 1. Age distribution (percentage) of children 1-59 months of age hospitalized with Haemophilus influenzae type b or with Streptococcus pneumoniae in Guatemala City, Guatemala, 1 October 1996-31 January 1999
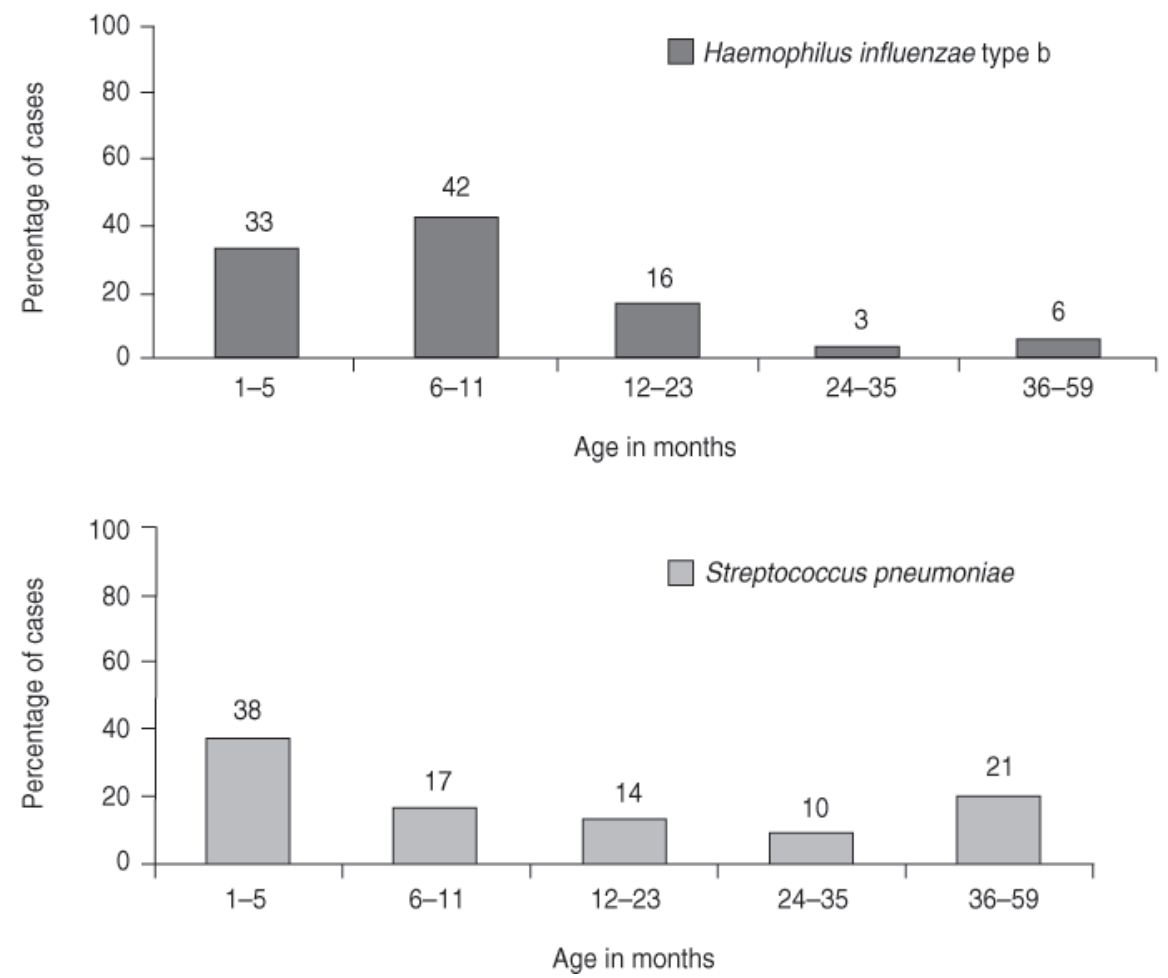

FIGURE 2. Seasonality of meningitis by etiology in children 1-59 months of age, Guatemala City, Guatemala, 1 October 1996-31 January 1999

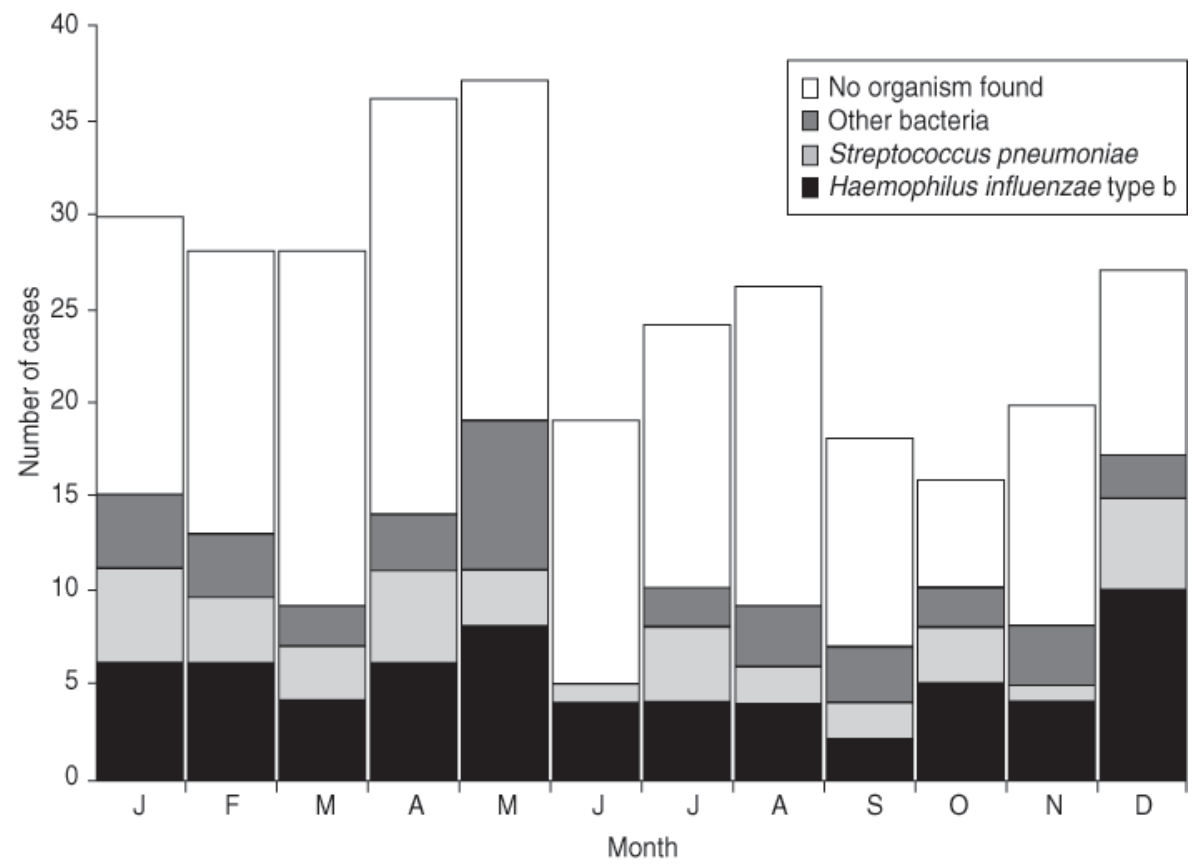

CSF white blood cell count was 389 with a glucose of $1 \mathrm{mg} / \mathrm{dL}$, and protein of $155 \mathrm{mg} / \mathrm{dL}$.

Antibiotic therapy before hospital admission was reported for 156 of the 357 children with meningitis $(43.7 \%)$. Among the 37 children with Hib meningitis who received antibiotics before admission, 19 of them (51.4\%) had a positive CSF or blood culture, while 26 of the $34(76.5 \%)$ who had not received prior antibiotics had positive CSF cultures $(P=0.05)$. Similarly, among children with $S$. pneumoniae meningitis, 9 of the 16 children (56.3\%) with prior antibiotic use had positive CSF cultures, but 27 of the 30 children $(90.0 \%)$ with no prior antibiotics had positive CSF cultures $(P=0.02)$.

The average incidence rate for meningitis of any cause was 85.4 per 100000 children/year among children under 5 years of age in Guatemala City; the rate for Hib meningitis was 13.8 per 100 000 and for S. pneumoniae meningitis, 11.7 per 100000 children. Fifty-four percent of meningitis occurred prior to 6 months of age and $79.6 \%$ before 12 months of age. Of the 71 children with Hib meningitis, 23 of them $(32.4 \%)$ were younger than 6 months of age, and 27 of the 46 children with S. pneumoniae meningitis (58.7\%) were also less than 6 months of age. Of the 35 children with meningitis due to Neisseria meningitidis, Salmonella spp., Escherichia coli, Pseudomonas spp., and other enteric organisms, 22 of them $(62.9 \%)$ had onset of disease between 1 and 6 months of age. The age distribution for children with no organism identified from CSF was similar to the age distribution for confirmed bacterial meningitis. A majority $(59.4 \%)$ of children with meningitis presented during the dry season (December through May), but no seasonal pattern was observed for meningitis caused by Hib or S. pneumoniae (Figure 2).

The median CSF white blood cell count for children with bacterial meningitis was $330 / \mathrm{mm}^{3}$. The CSF contained under $100 \mathrm{WBC} / \mathrm{mm}^{3}$ in $28.6 \%$ of children with Hib and $32.6 \%$ of children with S. pneumoniae meningitis (Figure 3 ). Of the 71 children with Hib meningitis, 5 of them $(7.0 \%)$ had 
FIGURE 3. Distribution (percentage) of cerebrospinal fluid (CSF) white blood cell count by etiology in children 1-59 months of age with meningitis, Guatemala City, Guatemala, 1 October 1996-31 January 1999
Haemophilus influenzae type b

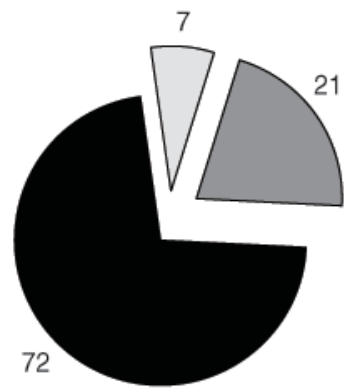

Streptococcus pneumoniae

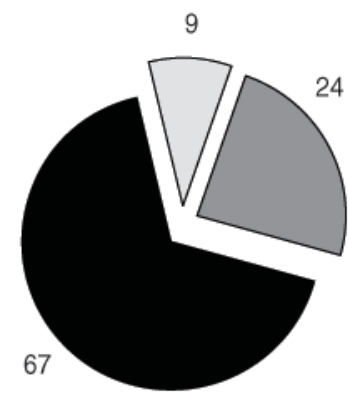

No organism found

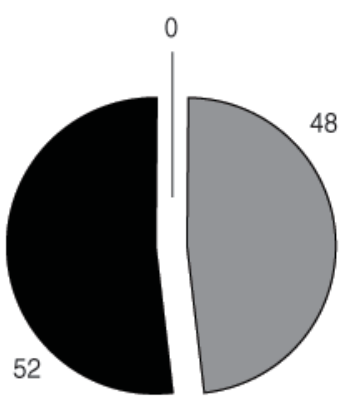

CSF white blood cell count categories
8.1 months. A chest radiograph was obtained on 692 of the 725 children with pneumonia $(95.4 \%)$; lobar or segmental consolidation was observed in 463 of the $692(66.9 \%)$ and pleural effusions in 65 of the $692(9.4 \%)$.

Just over one half (367 of 725 , or $50.6 \%$ ) of children with pneumonia received antibiotics before admission. Seven hundred of 725 (96.6\%) children with pneumonia had blood or pleural fluid cultures or pleural fluid latex testing. Hib was identified in the blood or pleural fluid in 24 of 700 children $(3.4 \%)$, and S. pneumoniae in 30 of the $700(4.3 \%)$. An organism was identified by culture or latex agglutination in pleural fluid from 41 of 68 children $(60.3 \%)$ with pleural effusion. One additional child with pleural effusion had Staphylococcus aureus isolated from the blood. Of the 68 children with pneumonia and pleural effusion, $S$. pneumoniae was identified in 28 of them $(41.2 \%)$, S. aureus in $8(11.8 \%)$, and $\mathrm{Hib}$ in $5(7.4 \%)$.

The overall CFR was $8.0 \%$ (58 of 725) (Table 3) for children with a primary diagnosis of pneumonia and 10.1\% (7 of 69) for children with pneumonia and pleural effusion.

\section{Sepsis}

\section{Pneumonia}

Seven hundred and twenty-five children had a primary diagnosis of pneumonia; 425 of them (58.6\%) were male. Of the 725, 267 of them $(36.8 \%)$ were under 6 months of age, and 204 of them $(28.1 \%)$ were between 6 and 12 months of age. The median age for children with primary pneumonia was
Presumptive sepsis was diagnosed on admission in 164 children; 7 of these children also had meningitis, 119 also had pneumonia, and 4 also had meningitis and pneumonia. The median age was 5.3 months for children with presumptive sepsis, and 58.5\% (96 of 164 were male. Of the 164 children, 24 children with presumptive Twenty-four additional children who had $<100 \mathrm{WBC} / \mathrm{mm}^{3}$ in the CSF met the WHO criteria for probable bacterial meningitis based on CSF protein or glucose. None of these children had a positive blood or CSF culture or latex agglutination test.

The overall case fatality rate (CFR) for meningitis was $23.0 \%$ (Table 2). Children with $S$. pneumoniae meningitis had a higher CFR than children with Hib meningitis (37.0\% vs. $14.1 \%$, $P=0.01)$. Children with no organism identified by culture or antigen detection had a CFR of $18.0 \%$. The CFR for

TABLE 2. Case fatality rate by etiology for children with meningitis, Guatemala City, Guatemala, 1 October 1996-31 January 1999

\begin{tabular}{lccc}
\hline \multicolumn{1}{c}{ Etiology } & $\begin{array}{c}\text { No. of } \\
\text { children studied }\end{array}$ & $\begin{array}{c}\text { No. of } \\
\text { deaths }\end{array}$ & $\begin{array}{c}\text { Case fatality } \\
\text { rate (\%) }\end{array}$ \\
\hline Haemophilus influenzae type & 71 & 10 & 14.1 \\
Streptococcus pneumoniae & 46 & 17 & 37.0 \\
Other bacteria & 40 & 19 & 47.5 \\
No organisms found & 200 & 36 & 18.0 \\
$\quad$ Total & 357 & 82 & 23.0 \\
\hline
\end{tabular}


TABLE 3. Case fatality rate by diagnosis, Guatemala City, Guatemala, 1 October 1996-31 January 1999

\begin{tabular}{lccc}
\hline \multicolumn{1}{c}{ Diagnosis } & $\begin{array}{c}\text { No. of } \\
\text { children studied }\end{array}$ & $\begin{array}{c}\text { No. of } \\
\text { deaths }\end{array}$ & $\begin{array}{c}\text { Case fatality } \\
\text { rate }(\%)\end{array}$ \\
\hline Meningitis & 357 & 82 & 23.0 \\
Pneumonia & 725 & 58 & 8.0 \\
Sepsis & 34 & 6 & 17.7 \\
Cellulitis & 60 & 0 & 0.0 \\
Septic arthritis & 9 & $1^{\text {a }}$ & 11.1 \\
Epiglottitis & 3 & 1 & 33.3 \\
Other & 15 & 1 & 6.7 \\
$\quad$ Total & 1203 & 149 & 12.4 \\
\hline
\end{tabular}

a This patient also had trauma.

sepsis $(14.6 \%)$ had an organism isolated from blood. Thirty-four of the $164(20.7 \%)$ children with presumptive sepsis were given the final diagnosis of sepsis, as no other focal infection was identified. Hib was identified in 3 of the 33 children $(9.1 \%)$ with sepsis who had a blood culture, and S. pneumoniae in 1 child $(3.0 \%)$.

\section{DISCUSSION}

The use of improved culture methods and latex agglutination antigen detection resulted in significantly increased rates of identification of Hib and S. pneumoniae as causes of bacterial invasive diseases in Guatemalan children. Other factors contributing to the prior underestimation of Hib and S. pneumoniae as important causes of severe disease include infrequently obtained blood cultures and high rates of antibiotic use prior to hospitalization. The estimated annual incidence of $\mathrm{Hib}$ and S. pneumoniae meningitis for children under 5 years of age in this population was lower than what has been observed in some other developing countries $(4,5,15,16)$. The true incidence is probably higher than 13.8 per 100000 , given the frequent use of antibiotics prior to hospitalization and the high CFR (18.0\%) in children with negative CSF cultures and negative latex agglutination antigen detection tests. Other investigators have shown that prior antibiotic ther- apy was associated with decreased concentrations of bacteria in the CSF, and many children with culture-negative meningitis have evidence of a bacterial etiology $(17,18)$. In this study the likelihood of obtaining a positive culture for children with other evidence of Hib or S. pneumoniae meningitis was significantly lower for children who had reported prior antibiotic therapy than for untreated children.

The high CFRs for Hib meningitis and for S. pneumoniae meningitis were consistent with observations in other developing countries (4-8). The higher CFR for children with meningitis residing outside of Guatemala City was most likely due to delayed therapy and selective referral of children with more severe disease.

Although children with proven bacterial meningitis generally have high CSF white blood cell counts, using a cutoff point of $>100 \mathrm{WBC} / \mathrm{mm}^{3}$ to define bacterial meningitis would have resulted in missing nine children with Hib or S. pneumoniae meningitis (14). None of the children with fewer than $100 \mathrm{WBC} / \mathrm{mm}^{3}$ in the CSF who met the WHO criteria for possible meningitis based on elevated CSF protein or low glucose had evidence of bacterial etiology based on culture or latex agglutination testing of CSF. We believe that a simplified definition of $\geq 10$ $\mathrm{WBC} / \mathrm{mm}^{3}$ is a better screening criterion for suspect meningitis.

In the 1980s, before the introduction of Hib conjugate vaccines in the
United States and other countries where blood cultures were obtained more commonly, meningitis constituted approximately $50 \%$ of all invasive Hib disease $(2,4)$. However, meningitis constituted $66.4 \%$ of all invasive $\mathrm{Hib}$ disease diagnosed in Guatemalan children, most likely due to decreased detection of nonmeningitis Hib disease in children referred to hospitals.

The cases of pneumonia due to Hib and S. pneumoniae in this study are undoubtedly an underestimate of the true burden of disease due to these organisms because of the low use of blood cultures in children presenting with suspect pneumonia and the treatment of many children with pneumonia as outpatients. During the first year of the study we attempted to increase the identification of $\mathrm{Hib}$ and $S$. pneumoniae in children presenting with sepsis or pneumonia by testing sera using latex agglutination. Latex agglutination for testing heated sera or pleural fluid resulted in good sensitivity and specificity for detection of Hib in other studies (19-21). While we were able to identify several cases of Hib disease, the cost-effectiveness of this test is low.

Surveillance for target diseases is important to help understand the potential value of vaccines that are under consideration for introduction into immunization programs. Conjugate $\mathrm{Hib}$ and S. pneumoniae vaccines could prevent many of the serious infections resulting in hospitalization of Guatemalan children $(6,9,13,22-25)$. An evaluation of the potential impact of Hib conjugate vaccine is under way following the introduction of this vaccine in the Hospital General del Instituto Guatemalteco de Seguridad Social.

Acknowledgments. This study was supported by grants from GlaxoSmithKline Biologicals and the World Health Organization. Some latex agglutination test kits and IsoVitaleX supplements for blood cultures were kindly provided by Becton Dickinson Microbiology Systems. We are particularly grateful to the physicians and 
nurses of the Hospital General San Juan de Dios, Hospital Roosevelt, and the Hospital General del Instituto Guatemalteco de Seguridad Social for enrolling and caring for these patients, to James D. Dick for his contributions to the design and improvement of the microbiology methods employed, to Bonnie King for data management, and to Melissa Romine and Tina Proveaux for their assistance with manuscript preparation.

\section{REFERENCES}

1. Adams WG, Deaver KA, Cochi SL, Plikaytis BD, Zell ER, Broome CV, et al. Decline of childhood Haemophilus influenzae type $\mathrm{b}$ (Hib) disease in the Hib vaccine era. JAMA 1993;269(2):221-226.

2. Broome CV. Epidemiology of Haemophilus influenzae type $\mathrm{b}$ infections in the United States. Pediatr Infect Dis J 1987;6(8):779782.

3. Cochi SL, Broome CV, Hightower AW. Immunization of US children with Hemophilus influenzae type $\mathrm{b}$ polysaccharide vaccine. A cost-effectiveness model of strategy assessment. JAMA 1985;253(4): 521-529.

4. Peltola H. Worldwide Haemophilus influenzae type $\mathrm{b}$ disease at the beginning of the 21st century: global analysis of the disease burden 25 years after the use of the polysaccharide vaccine and a decade after the advent of conjugates. Clin Microb Rev 2000;13:302-317.

5. Levine OS, Schwartz B, Pierce N, Kane M. Development, evaluation and implementation of Haemophilus influenzae type $\mathrm{b}$ vaccines for children in developing countries: current status and priority actions. Pediatr Infect Dis J 1998:17:S95-112.

6. Levine OS, Lagos R, Munoz A, Villaroel J, Alvarez AM, Abrego P, et al. Defining the burden of pneumonia in children preventable by vaccination against Haemophilus influenzae type $\mathrm{b}$. Pediatr Infect Dis J 1999;18(12):1060-1064.

7. Peltola H. Haemophilus influenzae type b disease and vaccination in Latin America and the Caribbean. Pediatr Infect Dis J 1997;16(8):780-787.

8. Peltola H. Need for Haemophilus influenzae type $b$ vaccination in Asia as evidenced by epidemiology of bacterial meningitis. Pediatr Infect Dis J 1998;17(9 Suppl): S148-151.

9. Mulholland K, Hilton S, Adegbola R, Usen S, Oparaugo A, Omosigho C, et al. Randomised trial of Haemophilus influen$z a e$ type-b tetanus protein conjugate vaccine for prevention of pneumonia and meningitis in Gambian infants. Lancet 1997;349(9060):1191-1197.

10. Salih MA, Khaleefa OH, Bushara M, Taha ZB, Musa ZA, Kamil I, et al. Long term sequelae of childhood acute bacterial meningitis in a developing country. A study from the Sudan. Scand J Infect Dis 1991;23(2):175-182.

11. World Health Organization. Antimicrobial and support therapy for bacterial meningitis in children: report of the meeting of 18-20 June, 1997, Geneva, Switzerland. Geneva: WHO; 1998. Available from: http://www.who.intemc-documents/ meningitis/whoemcbac982c.html [Internet site]. Accessed 19 February 2001.

12. Molyneux E, Walsh A, Phiri A, Molyneux $M$. Acute bacterial meningitis in children admitted to the Queen Elizabeth Central Hospital, Blantyre, Malawi in 1996-97. Trop Med Int Health 1998;3(8):610-618.

13. Mulholland EK, Adegbola RA. The Gambian Haemophilus influenzae type b vaccine trial: what does it tell us about the burden of Haemophilus influenzae type $\mathrm{b}$ disease? Pediatr Infect Dis J 1998;17(9 Suppl): S123-125.

14. Levine OS, Schuchat A, Schwartz B, Wenger JD, Elliot J. Generic protocol for population-based surveillance of Haemophilus influenzae type b. Geneva: World Health Organization, Global Programme for Vaccines and Immunization; 1997. (WHO/VRD/GEN/95.05).

15. Limcangco MR, Salole EG, Armour CL. Epidemiology of Haemophilus influenzae type $\mathrm{b}$ meningitis in Manila, Philippines, 1994 to 1996. Pediatr Infect Dis J 2000; 19(1):7-11.

16. Dagan R, Fraser D, Greif Z, Keller N, Kaufstein M, Shazberg G, et al. A nationwide prospective surveillance study in Israel to document pediatric invasive infections, with an emphasis on Haemophilus influenzae type $\mathrm{b}$ infections. Israeli Pediatric Bacteremia and Meningitis Group. Pediatr Infect Dis J 1998;17(9 Suppl): S198-203.

17. Shoma S, Rahman M, Yasmin M. Rapid detection of Haemophilus influenzae type $\mathrm{b}$ in Bangladeshi children with pneumonia and meningitis by PCR and analysis of antimicrobial resistance. J Health Popul Nut 2001;19(4):268-274.

18. Feldman WE. Effect of prior antibiotic therapy on concentrations of bacteria in CSF. Am J Dis Child 1978;132(7):672-674.
19. Ajello GW, Bolan GA, Hayes PS, Lehmann D, Montgomery J, Feeley JC, et al. Commercial latex agglutination tests for detection of Haemophilus influenzae type $\mathrm{b}$ and Streptococcus pneumoniae antigens in patients with bacteremic pneumonia. J Clin Microbiol 1987;25(8):1388-1391.

20. Rubin LG, Carmody L. Pneumococcal and Haemophilus influenzae type $\mathrm{b}$ antigen detection in children at risk for occult bacteremia. Pediatrics 1987;80(1):92-96.

21. Boersma WG, Lowenberg A, Holloway Y, Kuttschrutter H, Snijder JA, Koeter GH. Rapid detection of pneumococcal antigen in pleural fluid of patients with community acquired pneumonia. Thorax 1993; 48(2):160-162.

22. Levine OS, Ortiz E, Contreras R, Lagos R, Vial P, Misraji A, et al. Cost-benefit analysis for the use of Haemophilus influenzae type b conjugate vaccine in Santiago, Chile. Am J Epidemiol 1993;137(11):12211228.

23. Lagos R, Levine OS, Avendano A, Horwitz I, Levine MM. The introduction of routine Haemophilus influenzae type b conjugate vaccine in Chile: a framework for evaluating new vaccines in newly industrializing countries. Pediatr Infect Dis J 1998;17(9 Suppl):S139-148.

24. Wenger JD, DiFabio JL, Landaverde JM, Levine OS, Gaafar T. Introduction of Hib conjugate vaccines in the non-industrialized world: experience of four 'newly adopting' countries. Vaccine 1999;18: 736742 .

25. Mulholland $\mathrm{K}$, Levine $\mathrm{O}$, Nohynek $\mathrm{H}$, Greenwood BM. Evaluation of vaccines for the prevention of pneumonia in children in developing countries. Epidemiol Rev 1999;21(1):43-55.

Manuscript received 27 September 2002. Revised version accepted for publication on 23 July 2003. 
RESUMEN Objetivo. Determinar las características epidemiológicas de las infecciones invasoras por Haemophilus influenzae tipo b (Hib) y Streptococcus pneumoniae en niños hospitalizados en Guatemala. La importancia de este tema radica en que la vacunación con-

Meningitis y neumonía en niños guatemaltecos: importancia de Haemophilus influenzae tipo b y de Streptococcus pneumoniae tra Hib no ha sido incorporada a los programas de inmunización establecidos en Guatemala y en que los registros hospitalarios de 1995 indicaban una baja incidencia de meningitis e infecciones invasoras causadas por Hib y S. pneumoniae.

Métodos. Los niños hospitalizados en la Ciudad de Guatemala con signos clínicos de infección bacteriana se estudiaron en busca de indicios de infección por Hib o S. pneumoniae. Se cultivaron líquidos corporales normalmente estériles y se hicieron pruebas de detección de antígenos en líquidos cefalorraquídeo (LCR) y pleural.

Resultados. De los 1203 niños de 1 a 59 meses de edad hospitalizados en un período de 28 meses, $725(60,3 \%)$ tenían un diagnóstico primario de neumonía, $357(29,7 \%)$ de meningitis, 60 (5,0\%) de celulitis y 61 (5,1\%) de sepsis u otras afecciones. En 20,0\% de los niños con meningitis se detectó Hib y en $12,9 \%$ S. pneumoniae. La incidencia media anual de meningitis por Hib fue de 13,8 casos por 100000 niños menores de 5 años de edad; $32,4 \%$ de los casos de meningitis causados por Hib y $58,7 \%$ de los causados por S. pneumoniae ocurrieron en niños menores de 6 meses de edad. La tasa de letalidad fue de $14,1 \%, 37,0 \%$ y 18,0\%, respectivamente, para los casos de meningitis por Hib, por S. pneumoniae y con resultados negativos tanto en el cultivo como en las pruebas de detección de antígeno. El tratamiento previo con antibióticos fue frecuente y se vio asociado con una reducción significativa de resultados positivos en el cultivo de LCR en los niños que presentaban otros signos de meningitis por Hib o S. pneumoniae.

Conclusiones. El perfeccionamiento de la detección de casos, los métodos de cultivo y las pruebas de aglutinación con látex para la detección antigénica en LCR permitió identificar a Hib y S. pneumoniae como causas importantes de enfermedades graves en niños guatemaltecos. El empleo de un punto de corte de más de 10 leucocitos por milímetro cúbico de LCR mejoraría la sensibilidad de la detección de la meningitis bacteriana y ayudaría a calcular la carga de esta enfermedad en Guatemala y otros países en desarrollo. 